\title{
An Overview on Structure and Field Emission Properties of Carbon Nitride Films
}

\author{
Qiong Wang ${ }^{1}$ and Jinlong Jiang ${ }^{1,2}$ \\ ${ }^{1}$ Department of Physics, Lanzhou University of Technology, Lanzhou 730050, China \\ ${ }^{2}$ State Key Laboratory of Solid Lubrication, Lanzhou Institute of Chemical Physics, \\ Chinese Academy of Sciences, Lanzhou 730000, China \\ Correspondence should be addressed to Jinlong Jiang; jinlong@lut.cn
}

Received 26 February 2014; Revised 29 April 2014; Accepted 29 April 2014; Published 21 May 2014

Academic Editor: Jun Yang

Copyright (C) 2014 Q. Wang and J. Jiang. This is an open access article distributed under the Creative Commons Attribution License, which permits unrestricted use, distribution, and reproduction in any medium, provided the original work is properly cited.

Carbon nitride films have excellent properties and wide application prospects in the aspect of field emission properties. In this review structure characteristics and a variety of synthetic methods of carbon nitride film will be described. In the carbon nitrogen films, we mainly from the following three points: $\mathrm{sp}^{2} / \mathrm{sp}^{3}$ ratio, surface morphology and $\mathrm{N}$ content to discuss the change of field emission properties. Appropriate $\mathrm{sp}^{2} / \mathrm{sp}^{3}$ (about $1.0-1.25$ ) ratio, $\mathrm{N}$ content (about 8 at.\%-10 at.\%), and rough surfaces will strengthen the field emission properties.

\section{Introduction}

In the 1989, Liu and Cohen $[1,2]$ theoretically predicted the structure and physical properties of $\beta-\mathrm{C}_{3} \mathrm{~N}_{4}$ whose bulk modulus and hardness, compared with diamond, are more outstanding. Although great effort has been made in synthesis of this material, in most cases amorphous carbon nitrogen (a$\mathrm{CN}_{x}$ ) films instead of crystalline $\mathrm{C}_{3} \mathrm{~N}_{4}$ were obtained. Either crystalline $\mathrm{C}_{3} \mathrm{~N}_{4}$ or a- $\mathrm{CN}_{x}$ films have excellent performance. Studies have shown that carbon nitrogen $\left(\mathrm{CN}_{x}\right)$ films have excellent properties in terms of high hardness [3], wear resistance [4], hydrogen storage performance [5], and excellent field emission properties [6]. In the past three decades, diamond-like carbon films incorporated with nitrogen or called $\mathrm{CN}_{x}$ films have been extensively studied owing to their potential application as cold cathode materials in field emission displays (FED). In the case of the previous reports, the threshold fields of the pure DLC film were usually 3$20 \mathrm{~V} / \mu \mathrm{m}[7-9]$ and decreased to $1-12 \mathrm{~V} / \mu \mathrm{m}$ after nitrogen incorporation [10-12]. In the past few years, there has been considerable interest in electron field emission from $\mathrm{CN}_{x}$ films. In addition, the structures and synthesis methods of $\mathrm{CN}_{x}$ films are diverse, so they have attracted much attention.

\section{The Structures of $\mathbf{C N}_{x}$ Films}

2.1. The Structures of Crystalline Phase $\mathrm{CN}_{x}$ Films. Teter and Hemley through the theoretical calculation have predicted five kinds of crystalline phase structures of $\mathrm{C}_{3} \mathrm{~N}_{4}$ : alpha $\mathrm{C}_{3} \mathrm{~N}_{4}\left(\alpha-\mathrm{C}_{3} \mathrm{~N}_{4}\right)$, beta $\mathrm{C}_{3} \mathrm{~N}_{4}\left(\beta-\mathrm{C}_{3} \mathrm{~N}_{4}\right)$, cubic $\mathrm{C}_{3} \mathrm{~N}_{4}\left(\mathrm{c}-\mathrm{C}_{3} \mathrm{~N}_{4}\right)$, pseudo-cubic $\mathrm{C}_{3} \mathrm{~N}_{4}\left(\mathrm{pc}-\mathrm{C}_{3} \mathrm{~N}_{4}\right)$, and graphite $\mathrm{C}_{3} \mathrm{~N}_{4}\left(\mathrm{~g}-\mathrm{C}_{3} \mathrm{~N}_{4}\right)$ [13]. In addition, these crystal structures have been found and reported in experiments [14-17]. The $\alpha-\mathrm{C}_{3} \mathrm{~N}_{4}$ is earlier obtained by Yu et al. [18]. They used the calculation method of quantum mechanics clusters model and got $\alpha-\mathrm{C}_{3} \mathrm{~N}_{4}$ by optimization crystal structure of simulative $\mathrm{C}_{3} \mathrm{~N}_{4}$. The $\alpha-\mathrm{C}_{3} \mathrm{~N}_{4}$ has crystal plane cascade order of crystal structure, by $\mathrm{ABAB}$ pattern to stack. In the structure of $\alpha-\mathrm{C}_{3} \mathrm{~N}_{4}, \mathrm{C}$ and $\mathrm{N}$ atoms connection by $\mathrm{sp}^{3}$ key formed a tetrahedron structure. Liu and Cohen [1] predicted the existence of $\beta-\mathrm{C}_{3} \mathrm{~N}_{4}$ using band theory of first principles and prepared $\beta-C_{3} \mathrm{~N}_{4}$ based on $\beta$ $\mathrm{Si}_{3} \mathrm{~N}_{4}$ crystal structure. They previewed that the structure of $\beta-C_{3} N_{4}$ is the hexagonal containing 14 atoms per unit cell. As a new kind of superhard material, $\beta-\mathrm{C}_{3} \mathrm{~N}_{4}$ got more extensive research; its structure is shown in Figure 1 . The $c-\mathrm{C}_{3} \mathrm{~N}_{4}$ was first reported by Teter and Hemley [13]. They suggested the structure of $c-\mathrm{C}_{3} \mathrm{~N}_{4}$ using the conjugate gradient method 
TABLE 1: The structure parameters of crystal, bulk moduli $B$, and total energies $E_{0}$ for five kinds of the predicted carbon nitride crystals.

\begin{tabular}{|c|c|c|c|c|c|}
\hline & $\alpha-\mathrm{C}_{3} \mathrm{~N}_{4}$ & $\beta-\mathrm{C}_{3} \mathrm{~N}_{4}$ & Cubic- $\mathrm{C}_{3} \mathrm{~N}_{4}$ & Pseudocubic- $\mathrm{C}_{3} \mathrm{~N}_{4}$ & Graphite- $\mathrm{C}_{3} \mathrm{~N}_{4}$ \\
\hline Space group & P31c(159) & P3(143) & $\mathrm{I} \overline{4} 3 \mathrm{~d}(220)$ & $\mathrm{p} \overline{4} 2 \mathrm{~m}(111)$ & P̄̄m2(187) \\
\hline$Z$ & 4 & 2 & 4 & 1 & 2 \\
\hline$a(\AA)$ & 6.4665 & 6.4017 & 5.3973 & 3.4232 & 4.7420 \\
\hline$c(\AA)$ & 4.7097 & 2.4041 & & & 6.7205 \\
\hline$B_{0}(\mathrm{GPa})$ & 425 & 451 & 496 & 448 & \\
\hline$E_{0}$ (eV/unit) & -1598.669 & -1598.403 & -1597.388 & -1597.225 & -1598.71 \\
\hline
\end{tabular}

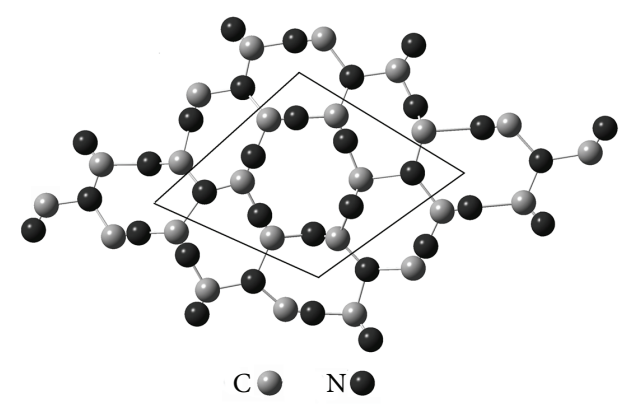

FIGURE 1: Schematic atomic structure of $\beta-\mathrm{C}_{3} \mathrm{~N}_{4}$.

and found it has a similar structural characteristic with the $\mathrm{Zn}_{2} \mathrm{SiO}_{4}$. Liu and Wentzcovitch [19] proposed pc- $\mathrm{C}_{3} \mathrm{~N}_{4}$ crystal structure based on the structure of cubic $\mathrm{ZnS}$ removed a quarter of $\mathrm{Zn}$ atom. They found that $\mathrm{pc}-\mathrm{C}_{3} \mathrm{~N}_{4}$ and $\beta-\mathrm{C}_{3} \mathrm{~N}_{4}$ have similar crystal structures. The $\mathrm{g}_{-} \mathrm{C}_{3} \mathrm{~N}_{4}$ has a variety of structures model. Liu and Wentzcovitch [19] proposed a rhombus g- $\mathrm{C}_{3} \mathrm{~N}_{4}$ crystal structure described as ABCABC... pattern to stack by calculation. However, Teter and Hemley [13] believed the mode of $\mathrm{g}-\mathrm{C}_{3} \mathrm{~N}_{4}$ is hexagonal graphite structure in which the arrangement of atoms is along the $\mathrm{C}$ axis and crystal structures are based on the $\mathrm{ABAB}$ pattern to stack [20].

In those structures of $\mathrm{C}_{3} \mathrm{~N}_{4}$, the g- $\mathrm{C}_{3} \mathrm{~N}_{4}$ has the most stable structure, but others have the superhard characteristics that it does not have. In the superhard structures of $\mathrm{C}_{3} \mathrm{~N}_{4}$, $\alpha-\mathrm{C}_{3} \mathrm{~N}_{4}$ is the most stable structure. In a single cell, the volume of $\mathrm{g}-\mathrm{C}_{3} \mathrm{~N}_{4}, \alpha-\mathrm{C}_{3} \mathrm{~N}_{4}, \beta-\mathrm{C}_{3} \mathrm{~N}_{4}, \mathrm{c}-\mathrm{C}_{3} \mathrm{~N}_{4}$, and pc- $\mathrm{C}_{3} \mathrm{~N}_{4}$ subsequently decreases; however, their energy increases in turn. Table 1 shows the structure parameters of crystal, bulk modulus $B$ and total energies $E_{0}$ for five kinds of the predicted carbon nitride crystals. In order to prepare the $\mathrm{C}_{3} \mathrm{~N}_{4}$ crystalline, carbon and nitrogen ratio of precursors should be as close as possible to the theoretical value of 1.33 . The researchers can also adopt appropriate methods to improve the reaction temperature, which can help the molecular fracture of the precursors.

2.2. The Structures of Amorphous $\mathrm{CN}_{x}$. Because carbon and nitrogen have the characteristic of various valence states forming bonding, therefore, in a- $\mathrm{CN}_{x}$ films there are diverse of valence bond structures, as shown in Figure 2 [21]. In a$\mathrm{CN}_{x}$ films, N/C ratio depended on preparation methods of the films and parameters of the technique. Studies have found that some $\mathrm{C}_{3} \mathrm{~N}_{4}$ defect structures and amorphous structures of $\mathrm{CN}_{x}$ films are still the metastable structures, but with the increase of $\mathrm{N}$ vacancy, these two kinds of structure of $\mathrm{CN}_{x}$ material reduce in bulk modulus. Researches show that the hardness of a-CN $\mathrm{CN}_{x}$ films which be reached is $15 \mathrm{GPa}-50 \mathrm{GPa}$. At the same time, a- $\mathrm{CN}_{x}$ films have very excellent tribological properties. The structural characteristics, composition of materials, and crystallinity of $\mathrm{CN}_{x}$ films can be characterized and analyzed by XRD, XPS, and Raman, techniques. From the current results, the superior mechanical properties, good heat conductivity properties, and excellent field emission properties make a-CN $\mathrm{CN}_{x}$ films win a place in the new materials.

\section{The Preparation Methods of $\mathbf{C N}_{x}$ Films}

The research on syntheses and properties of carbon nitride $\left(\mathrm{CN}_{x}\right)$ films has aroused interest of scholars from different countries. $\mathrm{CN}_{x}$ films with particular properties have been synthesized whose structures and characteristics were reviewed $[22,23]$. The synthetic methods include physical vapor deposition (PVD), chemical vapor deposition (CVD), and so forth. These methods have led to amorphous $\mathrm{CN}_{x}$ films or in some cases formed carbon nitride crystallites structure embedded in an amorphous $\mathrm{CN}_{x}$ matrix.

3.1. Physical Vapor Deposition (PVD). Physical vapor deposition comprises magnetron sputtering, ion beam deposition (IBD), reaction sputtering, and pulsed laser deposition, and so forth. Reaction sputtering is the basic method for preparation of compound films. When used it to prepare $\mathrm{CN}_{x}$ films, the mass fraction of nitrogen is generally lower than $40 \%$. However, to form $\beta-C_{3} N_{4}$, system should include enough nitrogen and stoichiometric ratio should reach $57 \%$. Niu et al. [24] obtained the $\mathrm{CN}_{x}$ films on silicon substrate by using pulse laser evaporation $\mathrm{C}$ target, auxiliary deposition of atom nitrogen. Their studies found that $\mathrm{N}$ content reached $40 \%$ in the films and then $\mathrm{C}, \mathrm{N}$ atoms combined with nonpolar covalent bond. Subsequently, Sharma et al. [25] and Zhang et al. [26] also obtained $\mathrm{CN}_{x}$ films by a similar method. Mihailescu et al. [27] using ammonia instead of $\mathrm{N}_{2}$ produced hard $\mathrm{CN}_{x}$ films with carbon nitrogen single bond, double bond, and triple bond and then got that its optical band gap is $4.5 \mathrm{eV}$. Through analysis of the current study, people mostly get are mixture films which containing a various of crystal phases. Traditionally, these mixture films are called $\mathrm{CN}_{x}$ films. 


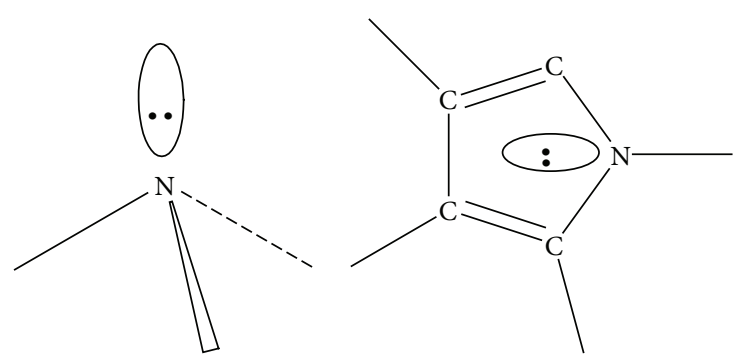

(a)

(b)

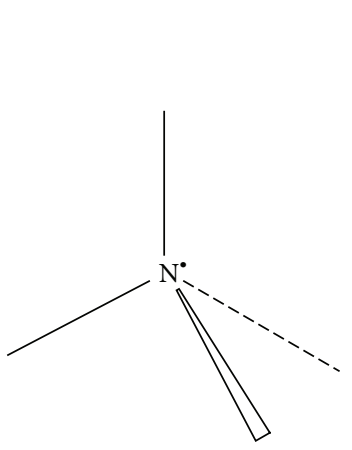

(c)

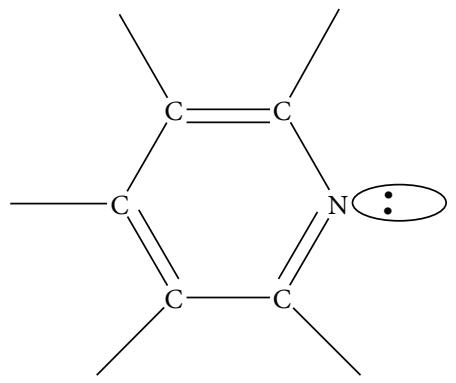

(e)

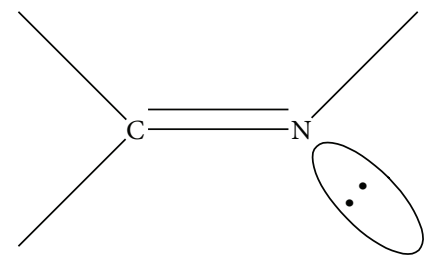

(g)

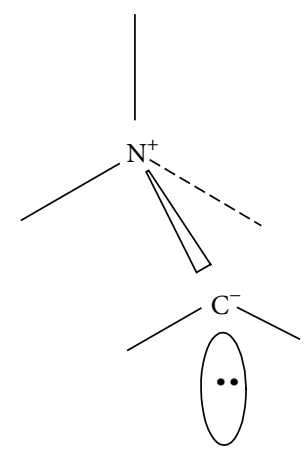

(d)

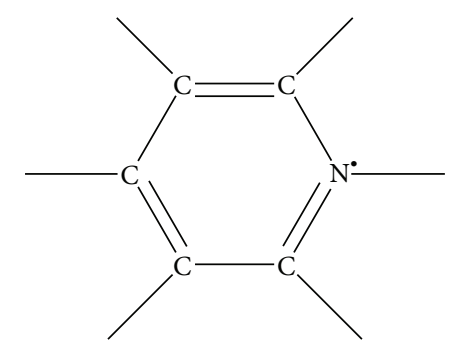

(f)

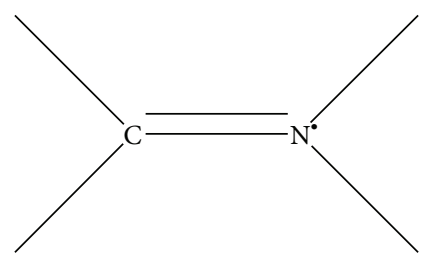

(h)

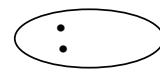

(i)

(j)

Figure 2: The possible bonding configuration in a- $\mathrm{CN}_{x}$ films: (a)-(d) $\mathrm{N} \mathrm{sp}^{3}$ hybridization; (e)-(f) $\mathrm{N}$ atom in benzene; (g)-(h) $\mathrm{N}$ sp ${ }^{2}$ hybridization (linear); (i) $\mathrm{N} \mathrm{sp}^{1}$ hybridization (nit rile); (j) $\mathrm{N} \mathrm{sp}^{1}$ hybridization (nitrile-like, autocompensation effect).

3.2. Chemical Vapor Deposition (CVD). Chemical vapor deposition achieved good results in the synthesis of carbon nitride films compared with other synthetic methods. CVD method is mainly used for one or more elements belonging to the film, so that these elements generate chemical reaction on the surface of the substrate and then generate films. CVD methods mainly include electron cyclotron resonance, hot filament assisted, DC glow discharge, radiofrequency discharge, and microwave plasma chemical vapor deposition.
Bias of auxiliary hot filament chemical vapor deposition (HFCVD) is one of the traditional devices used in the deposition of diamond films. Wang et al. $[32,33]$ got $\mathrm{CN}_{x}$ films on Ni substrate by using HFCVD method firstly. Because preparation of the films is more likely to generate $\mathrm{C}-\mathrm{H}$ and $\mathrm{N}-$ $\mathrm{H}$ bonds under the CVD conditions, so most of the $\mathrm{CN}_{x}$ films are amorphous. Many researches are focused on the mechanical properties and field emission performance of the thin films. Based on previous researches, when CVD methods 
TABLE 2: Optimal sp $\mathrm{sp}^{2} / \mathrm{sp}^{3}$ ratio of amorphous carbon films which can be used as a reference of $\mathrm{CN}_{x}$ films.

\begin{tabular}{|c|c|c|c|c|c|}
\hline & $\mathrm{sp}^{2} / \mathrm{sp}^{3}$ ratio & Preparation method & $\begin{array}{l}\text { Turn-on electric field } \\
\qquad\left(F_{T}\right)\end{array}$ & Highest current density & Reference \\
\hline DLC films & $0.85-1.0$ & $\begin{array}{c}\text { Microwave plasma } \\
\text { chemical vapor deposition } \\
\text { (MPCVD) }\end{array}$ & $\begin{array}{l}10 \mathrm{~V} / \mu \mathrm{m} \text { (defined as the } \\
\text { low-end electric field to } \\
\text { emit electrons) }\end{array}$ & - & {$[28]$} \\
\hline $\mathrm{a}-\mathrm{C}$ & 1.25 & MPCVD & $4.8 \mathrm{~V} / \mu \mathrm{m}\left(0.28 \mathrm{~mA} / \mathrm{cm}^{2}\right)$ & - & [29] \\
\hline Metal-DLC & 1.0 & Electrochemical deposition & $6.5 \mathrm{~V} / \mu \mathrm{m}\left(1 \mu \mathrm{A} / \mathrm{cm}^{2}\right)$ & $1.2 \mathrm{~mA} / \mathrm{cm}^{2}(23.5 \mathrm{~V} / \mu \mathrm{m})$ & {$[30]$} \\
\hline Metal-DLC & 1.2016 & Electrochemical deposition & $8.4 \mathrm{~V} / \mu \mathrm{m}\left(1 \mu \mathrm{A} / \mathrm{cm}^{2}\right)$ & $163.89 \mu \mathrm{A} / \mathrm{cm}^{2}(12.455 \mathrm{~V} / \mu \mathrm{m})$ & {$[31]$} \\
\hline
\end{tabular}

are used to prepare $\mathrm{CN}_{x}$ films, the choice of substrate materials is critical.

\section{Field Emission Properties of $\mathbf{C N}_{x}$ Films}

Field emission displays have high brightness, high resolution and vivid colors, fast response speed, and low energy consumption which can make true the advantages of flat displays and make it become the future direction of the display technology [34]. The preparation of cold cathode is the key factor in field emission display technology. Low-dimensional structure cold cathode materials with excellent field emission have broad application prospects in the vacuum microelectronic device. It is known that carbon-based materials such as diamond [28], diamond-like carbon, and carbon nanotubes $[35,36]$ are good cold cathode field emission materials. However, these materials still have many drawbacks [37-39], for DLC films are limited owing to its low total field emission current and high threshold fields, which have restricted the field emission properties. The incorporation of suitable amount of nitrogen into carbon films formed $\mathrm{CN}_{x}$ films which can enhance field emission properties of the materials. It is attributed to the weak donor activity of nitrogen that make the Fermi level rise [40],work function lower and formation of more $\mathrm{sp}^{2}$ clusters in films. The $\mathrm{sp}^{2} / \mathrm{sp}^{3}$ ratio and surface morphology of $\mathrm{CN}_{x}$ films may also affect the field emission properties [41].

4.1. The Influence of $s p^{2} / s p^{3}$ Ratio on Field Emission Properties. From the results of studies, the $\mathrm{sp}^{2} / \mathrm{sp}^{3}$ ratio in the DLC films increases with the increase of nitrogen doping [30, 4244]. The $\mathrm{sp}^{2}$ clusters have high electrical conductivity that has better ability to provide high currents [45]. These $\mathrm{sp}^{2}$ clusters forming caused electron delocalization and/or improved electron hop between the clusters. Moreover, these clusters were likely to be overlapped, which also further accelerated electrons transportation between the connecting clusters $[46,47]$. The electrons would be easily extracted from the film surface while the external electric field was applied, so high content of $\mathrm{sp}^{2}$ cluster plays a very important role in the field emission properties. These $\mathrm{sp}^{2}$ clusters with good connectivity act as a conductive channel in amorphous structures so that electrons can be launched into vacuum through this channel under the action of the outer electric field. With the increase of emission electron in films, the Fermi level rise, the work function, and surface potential barrier height of the material are reduced, and then the electron emits from the surface more easily $[48,49]$. In addition, the threshold field decreases when the $\mathrm{sp}^{2}$ clusters size increases [50]. However, Satyanarayana et al. [51-53] hold a different view with most researchers. They suggested that electron emission increases with the higher $\mathrm{sp}^{3}$ content and the field emission was not enhanced by an excessive amount of $\mathrm{sp}^{2}$-bonded carbon. This is due to a serious graphitization of films at a higher level of $\mathrm{sp}^{2}$ content.

From Table 2, it can be concluded that an optimum $\mathrm{sp}^{2} / \mathrm{sp}^{3}$ bonding ratio provides a high emission current density and a low turn-on electric field $\left(F_{T}\right)$ value. The $\mathrm{sp}^{3}$ bonding confers on $\mathrm{CN}_{x}$ film with low electron affinity and also a chemical and physical inertness that is invaluable for FED applications, with low electron affinity aid in electron emission to a vacuum. Shi et al. proposed a multiple step emission mechanism and the junction between $\mathrm{sp}^{2}$ and $\mathrm{sp}^{3}$ rich clusters provides an intermediate ladder for the electrons to climb up from the $\mathrm{sp}^{2}$ rich clusters to $\mathrm{sp}^{3}$ rich ones where they may have enough energy to overcome the small barrier to emit to vacuum [54]. As is shown in Table 3 , the $\mathrm{sp}^{2}$ clusters size plays an important role in electron field emission properties [55]. Table 3 shows that the size of $\mathrm{sp}^{2}$ aromatic clusters is in the range of 1.8-2.4 nm, according to the Tuinstra-Koenig (TK) relationship [56,57]. According to Tables 2 and 3 we suggest that in $\mathrm{CN}_{x}$ films what can effectively improve the field emission properties is the appropriate size and concentration $\left(\mathrm{sp}^{2} / \mathrm{sp}^{3}\right.$ ratio is about $\left.1.0-1.25\right)$ of $\mathrm{sp}^{2}$ clusters [58]; the more conductive $\mathrm{sp}^{2}$ phase should be surrounded by insulating $\mathrm{sp}^{3}$ matrix to form a conductive channels, which at the same time can ensure that the electronic can easily be launched into the vacuum, which can effectively improve the field emission properties.

\subsection{The Influence of Surface Morphology on Field Emission} Properties. The electron emission is strongly related to the surface roughness: rougher surface means that there are more dense protrusions in the film surface. Protrusive structures could further increase the field enhancement factor which can geometrically promote the field emission $[63,64]$. The $\mathrm{CN}_{x}$ films prepared by doping nitrogen into DLC films have a more rough surface morphology than DLC films $[65,66]$. So these $\mathrm{CN}_{x}$ films have a higher geometric enhancement factor compared with DLC films and also have lower threshold field.

Some methods can be used to process the surface of films, such as ion etching which can create surface roughness to 
TABle 3: Appropriate size of $\mathrm{sp}^{2}$ clusters.

\begin{tabular}{|c|c|c|c|c|c|}
\hline & Size of $\mathrm{sp}^{2}$ clusters $(\mathrm{nm})$ & Preparation method & $\begin{array}{l}\text { Turn-on electric field } \\
\left(F_{T}\right) \text { /threshold field } \\
\left(F_{\text {th }}\right)\end{array}$ & Current density & Reference \\
\hline $\begin{array}{l}\text { Ta-C (annealed in } \\
\text { nitrogen and acetylene } \\
\text { ambient) }\end{array}$ & 2 & $\begin{array}{c}\text { Filtered cathodic } \\
\text { vacuum arc } \\
\text { technique }\end{array}$ & $4.8 \mathrm{~V} / \mu \mathrm{m}\left(1 \mu \mathrm{A} / \mathrm{cm}^{2}\right)$ & - & {$[50]$} \\
\hline N-PPANI & 2.2 & $\begin{array}{l}\text { Pyrolysis of } \\
\text { polyaniline }\end{array}$ & $1.7 \mathrm{~V} / \mu \mathrm{m}\left(10 \mu \mathrm{A} / \mathrm{cm}^{2}\right)$ & - & [59] \\
\hline $\mathrm{CN}_{x}$ & $1.8-2.4$ & $\begin{array}{c}\text { Magnetron } \\
\text { sputtering of carbon } \\
\text { target }\end{array}$ & $4.0 \mathrm{~V} / \mu \mathrm{m}\left(1 \mu \mathrm{A} / \mathrm{cm}^{2}\right)$ & $10 \mu \mathrm{A} / \mathrm{cm}^{2}(11.0 \mathrm{~V} / \mu \mathrm{m})$ & {$[56]$} \\
\hline
\end{tabular}

TABle 4: Nitrogen content of the $\mathrm{CN}_{x}$ films.

\begin{tabular}{|c|c|c|c|c|c|}
\hline & $\mathrm{N}$ content (at.\%) & Preparation method & $\begin{array}{c}\text { Turn-on electric field } \\
\left(F_{T}\right) / \text { threshold field }\left(F_{\text {th }}\right)\end{array}$ & Current density & Reference \\
\hline $\mathrm{a}-\mathrm{C}: \mathrm{N}$ films & 8.0 & $\begin{array}{l}\text { Electron cyclotron } \\
\text { resonance plasma }\end{array}$ & 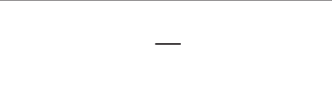 & - & {$[60]$} \\
\hline ta-C:N & 10 & $\begin{array}{l}\text { A pulsed filtered } \\
\text { vacuum arc } \\
\text { deposition }\end{array}$ & $4 \mathrm{~V} / \mu \mathrm{m}\left(1 \times 10^{-6} \mathrm{~A} / \mathrm{cm}^{2}\right)$ & - & {$[10]$} \\
\hline DLC:N & 10 & Electrodeposition & $11.8 \mathrm{~V} / \mu \mathrm{m}\left(1 \mu \mathrm{A} / \mathrm{mm}^{2}\right)$ & $59.5 \mu \mathrm{A} / \mathrm{mm}^{2}(24 \mathrm{~V} / \mu \mathrm{m})$ & {$[61]$} \\
\hline ta-C:N & 10.3 & $\begin{array}{c}\text { Filtered cathodic } \\
\text { vacuum arc } \\
\text { deposition }\end{array}$ & - & - & {$[62]$} \\
\hline
\end{tabular}

cause a field enhancement of the films. Songbo Wei et al. reported that, with increasing the bombarding energy, the film surface changed from smooth to a peak-and-valley structure, and the film surface became rougher. The root mean square (RMS) values of the $\mathrm{CN}_{x}$ films increased from $0.27 \mathrm{~nm}$ to $0.78 \mathrm{~nm}$ in this process [67]. Hart et al. and Shi et al. believe that hydrogen treatment on the surface of films can create $\mathrm{sp}^{2}$ clusters which would induce a field enhancement of the surface $[54,68]$, while Robertson think that, after treating with hydrogen, some areas of the surface will adsorb hydrogen and form $\mathrm{C}-\mathrm{H}$ dipole which would cause a nonuniform distribution of electric field and produce an electric field enhancement effect which is similar to the metal tip needle [37].

4.3. The Influence of $N$ Content on Field Emission Properties. It was found that the field emission of $\mathrm{CN}_{x}$ films depended on the $\mathrm{N}$ content and this effect dominated the effects of other parameters, such as $\mathrm{sp}^{3}$ content, band gap of the films, Fermi level position, and resistivity of the films. The effect is negative on field emission no matter too much or too little nitrogen doping into $\mathrm{CN}_{x}$ films and only the appropriate nitrogen content can enhance field emission properties [69]. As shown in Table 4, which is based on previous experimental results, it can be seen that the $\mathrm{CN}_{x}$ film containing 8 at.\%10 at. $\%$ nitrogen $[10,60-62,70]$ possesses enhanced field emission properties. A minimum for threshold field and a maximum for emission current density at this suitable $\mathrm{N}$ content were found. High levels of nitrogen additions are found to reduce field emission properties; from the above description we know that $\mathrm{N}$ incorporation into the DLC films favors formation of $\mathrm{sp}^{2}$ units and leads to serious graphitization of the $\mathrm{CN}_{x}$ films $[11,53]$. According to the proposal of Cutler et al.'s three-step field emission model, the emitted electrons are assumed to subject a three-step process. The first step is internal emission, the second step is electron transport, and the third step is vacuum emission $[10,54,71]$. The determinative within third step is the fraction of $\mathrm{sp}^{3}$ phase, since the $\mathrm{sp}^{3}$ phase carbon has a low electron affinity, and the $\mathrm{sp}^{3}$ phase is favorable for electron emission into vacuum [54]. So serious graphitization of the $\mathrm{CN}_{x}$ films is not conducive to the field emission. Vacuum emission is a determinative for the whole emission process.

In the first step, the determinative for emission is the value of band gap and Fermi level position. However, in the second step, the injected electrons transport across the $\mathrm{CN}_{x}$ films bulk, which is directly limited by the resistivity of the $\mathrm{CN}_{x}$ films [10]. From Figure 3 it can be seen that as the N content increases, the optical band gap reduces and Fermi level increases of $\mathrm{CN}_{x}$ films $[10,72]$. When the $\mathrm{N}$ content keeping at an optimum range the resistivity of the films decreases remarkably [62]. However, when the $\mathrm{N}$ content becomes higher than the appropriate value, Fermi level and band gap width do not move any more, the resistivity approaches gradually to a saturation value $[10,73]$.

\section{Conclusions}

For several decades, a variety of techniques have been used for the synthesis of $\mathrm{CN}_{x}$ films; in this paper PVD and CVD 


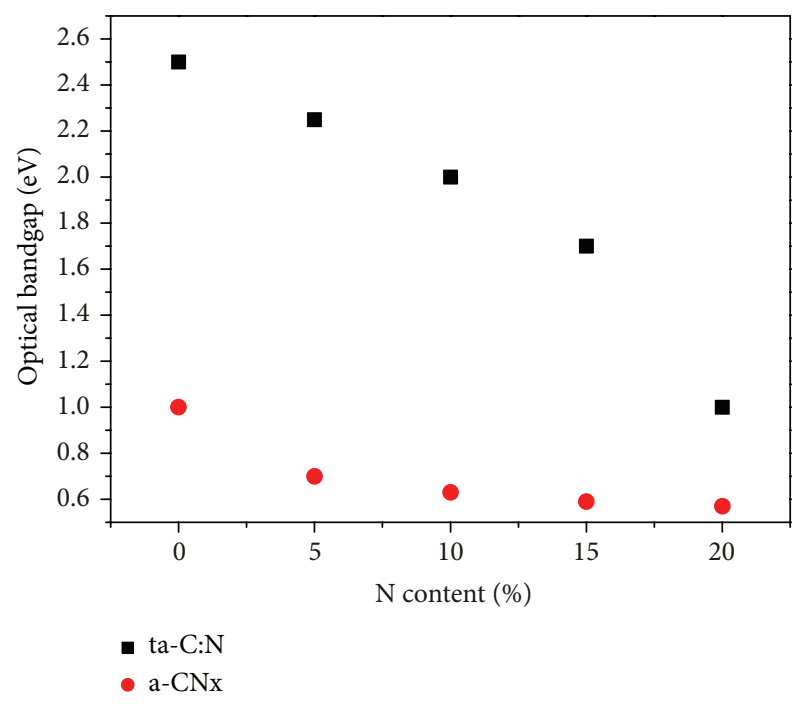

Figure 3: Optical band gap versus nitrogen content. Data from Zhang et al. [10] and Meškinis et al. [72].

methods have been introduced. The structures properties in crystalline and amorphous $\mathrm{CN}_{x}$ films have been elaborated in this paper.

The field emission properties of $\mathrm{CN}_{x}$ films are influenced by ratio of $\mathrm{sp}^{2} / \mathrm{sp}^{3}$, size of $\mathrm{sp}^{2}$ clusters, surface morphology, and $\mathrm{N}$ content of films. Appropriate $\mathrm{sp}^{2} / \mathrm{sp}^{3}$ ratio (about 1.01.25 ) and $\mathrm{N}$ content (about 8 at.\%-10 at.\%) will strengthen the field emission properties. When $\mathrm{N}$ contents remain at an optimum range, the optical band gap and resistivity reduce and Fermi level of $\mathrm{CN}_{x}$ films increases, which are important for enhancing field emission properties. Appropriate size of $\mathrm{sp}^{2}$ clusters is about $1.8-2.4 \mathrm{~nm}$. Doping nitrogen can enhance surface roughness of $\mathrm{CN}_{x}$ films; the $\mathrm{CN}_{x}$ films with rougher surface also have lower threshold field. So $\mathrm{CN}_{x}$ films with rough surface can improve the field emission properties.

\section{Conflict of Interests}

The authors declare that there is no conflict of interests regarding the publication of this paper.

\section{References}

[1] A. Y. Liu and M. L. Cohen, "Prediction of new low compressibility solids," Science, vol. 245, no. 4920, pp. 841-842, 1989.

[2] A. Y. Liu and M. L. Cohen, "Structural properties and electronic structure of low-compressibility materials: p-Si3N4 and hypothetical p- $\mathrm{C}_{3} \mathrm{~N}_{4}$," Physical Review, vol. 1341, pp. 10727-10734, 1990.

[3] W. C. Chan, B. Zhou, Y. W. Chuang, C. S. Lee, and S. T. Lee, "Synthesis, composition, surface roughness and mechanical properties of thin nitrogenated carbon films," Journal of Vacuum Science and Technology A, vol. 16, no. 3, pp. 1907-1910, 1998.

[4] C. J. Torng, J. M. Sivertsen, and J. H. Judy, "Structure and bonding studies of the $\mathrm{C}: \mathrm{N}$ thin solid films produced by RF Sputtering method," Journal of Materials Research, vol. 5, no. 11, pp. 2490-2496, 1990.
[5] Y. Ohkawara, S. Ohshio, T. Suzuki, K. Yatsui, H. Ito, and H. Saitoh, "Hydrogen storage in amorphous phase of hydrogenated carbon nitride," Japanese Journal of Applied Physics, vol. 41, no. 12, pp. 7508-7509, 2002.

[6] J. J. Li, W. T. Zheng, L. Sun et al., "Field emission from amorphous carbon nitride films deposited on silicon tip arrays," Chinese Physics Letters, vol. 20, no. 6, pp. 944-946, 2003.

[7] C. Wang, A. Garcia, D. C. Ingram, M. Lake, and M. E. Kordesch, "Cold field emission from CVD diamond films observed in emission electron microscopy," Electronics Letters, vol. 27, no. 16, pp. 1459-1461, 1991.

[8] K. Okano, S. Koiznmi, S. Ravi, P. Silva, and G. A. J. Amaratunga, "Low-threshold cold cathodes made of nitrogen-doped chemical-vapour-deposited diamond," Nature, vol. 381, pp. 140-141, 1996.

[9] D. S. Mao, W. Li, X. Wang, and X. H. Liu, "Diamond-like carbon films prepared by filtered arc deposition for electron field emission application," Surface and Coatings Technology, vol. 137, no. 1, pp. 1-5, 2001.

[10] X. W. Zhang, W. Y. Cheung, and S. P. Wong, "Field electron emission characteristics of nitrogenated tetrahedral amorphous carbon films," Thin Solid Films, vol. 429, no. 1-2, pp. 261-266, 2003.

[11] B. S. Satyanarayana, A. Hart, W. I. Milne, and J. Robertson, "Field emission from tetrahedral amorphous carbon," Diamond and Related Materials, vol. 7, pp. 656-659, 1998.

[12] E. Fogarassy, T. Szoreny, G. Pirio, J. Olivier, P. Legagneux, and P. Boher, "Field emission properties of a-CNx films prepared by pulsed laser deposition," Applied Physics A, vol. 76, no. 1, pp. 1519, 2003.

[13] D. M. Teter and R. J. Hemley, "Low-compressibility carbon nitrides," Science, vol. 271, no. 5245, pp. 53-55, 1996.

[14] Y. Tian, J. Z. Wang, W. F. Yu, R. Cao, Y. Song, and X. Ning, "Effect of acetic acid on electrochemical deposition of carbon-nitride thin film," Science in China, Series E: Technological Sciences, vol. 52, no. 6, pp. 1698-1702, 2009.

[15] Y. S. Gu, Z. J. Duan, H. G. Yi et al., "The preparation of crystalline $\beta-\mathrm{C}_{3} \mathrm{~N}_{4}$ film," Physics, vol. 26, no. 8, pp. 449-450, 1997.

[16] C. Li, C. B. Cao, and H. S. Zhu, "Electrodeposition of graphitelike carbon nitride thin films," Journal of Synthetic Crystals, vol. 32, no. 3, pp. 252-256, 2003.

[17] J. T. Zhang, C. B. Cao, and H. S. Zhu, "Preparation and photoelectrical properties of CNx films," Chinese Journal of Materials Research, vol. 17, no. 4, pp. 432-438, 2003.

[18] K. M. Yu, M. L. Cohen, E. E. Haller, W. L. Hansen, A. Y. Liu, and I. C. Wu, "Observation of crystalline $\mathrm{C}_{3} \mathrm{~N}_{4}$," Physical Review B, vol. 49, no. 7, pp. 5034-5037, 1994.

[19] A. Y. Liu and R. M. Wentzcovitch, "Stability of carbon nitride solids," Physical Review B, vol. 50, no. 14, pp. 10362-10365, 1994.

[20] D. L. Yu, Research on synthesis methods and crystal structures of carbon nitrides [Ph.D. thesis], Yanshan University, Hebei, China, December, 2001.

[21] B. Zheng, Theoretical study for amorphous carbon, amorphous carbon nitride and nanodiamond [Ph.D. thesis], Jilin University, Jilin, China, May, 2006.

[22] Z. B. Ma, "Progress in the synthesis and characterization of carbon nitride crystals," New Carbon Materials, vol. 21, no. 3, pp. 276-283, 2006.

[23] X. R. Liang, Y. L. Jiang, L. Y. Kong et al., "The synthesis, application and research progress of carbon nitride $\left(\mathrm{C}_{3} \mathrm{~N}_{4}\right)$ materials," The New Technology and New Process, vol. 1, pp. 88-90, 2013. 
[24] C. Niu, Y. Z. Lu, and C. M. Lieber, "Experimental realization of the covalent solid carbon nitride," Science, vol. 261, no. 5119, pp. 334-337, 1993.

[25] A. K. Sharma, P. Ayyub, M. S. Multani et al., "Synthesis of crystalline carbon nitride thin films by laser processing at a liquid-solid interface," Applied Physics Letters, vol. 69, no. 23, pp. 3489-3491, 1996.

[26] Z. J. Zhang, S. S. Fan, J. L. Huang, and C. M. Lieber, "Diamondlike properties in a single phase carbon nitride solid," Applied Physics Letters, vol. 68, no. 19, pp. 2639-2641, 1996.

[27] I. N. Mihailescu, E. Gyorgy, R. Alexandrescu et al., "Optical studies of carbon nitride thin films deposited by reactive pulsed laser ablation of a graphite target in low pressure ammonia," Thin Solid Films, vol. 323, no. 1-2, pp. 72-78, 1998.

[28] Y. C. Chen, X. Y. Zhong, B. Kabius, J. M. Hiller, N. H. Tai, and I. N. Lin, "Improvement of field emission performance on nitrogen ion implanted ultrananocrystalline diamond films through visualization of structure modifications," Diamond and Related Materials, vol. 20, no. 2, pp. 238-241, 2011.

[29] Z. L. Lu, B. L. Zhang, N. Yao, X. Y. Zhang, B. X. Ma, and Z. Q. Fan, "The effect of surface $\mathrm{sp}^{2} / \mathrm{sp}^{3}$ bonding ratios of carbon films on the field emission property," in Proceedings of the 5th International Vacuum Electron Sources Conference (IVESC '04), September 2004

[30] X. M. Ling, P. Z. Zhang, R. S. Li, D. W. Fan, and X. M. Yao, "Electron field emission of iron and cobalt-doped DLC films fabricated by electrochemical deposition," Surface and Interface Analysis, vol. 45, pp. 943-948, 2013.

[31] Q. Wang, S. L. Li, and S. H. Wan, "Investigation of field emission characteristics and microstructure of nickel-doped DLC nanocomposite films by electrochemical deposition," Physica E, vol. 46, pp. 89-96, 2012.

[32] E. G. Wang, Y. Chen, and L. P. Guo, "Preparation and structure of $\mathrm{C}_{3} \mathrm{~N}_{4}$-specimens on Ni substrate," Science in China A, vol. 27, no. 2, pp. 154-157, 1997.

[33] Y. Chen, L. P. Guo, and E. G. Wang, "Experimental evidence for alpha and beta -phases of pure crystalline $\mathrm{C}_{3} \mathrm{~N}_{4}$ in films deposited on nickel substrates," Philosophical Magazine Letters, vol. 75, no. 3, pp. 155-162, 1997.

[34] R. Wang and B. Wang, "A critical review of field electron emission thin film materials," Materials China, vol. 28, no. 3, pp. 6-12, 2009.

[35] B. Padya, D. Kalita, P. K. Jainl, G. Padmanabham, M. Ravi, and K. S. Bhat, "Nitrogen incorporated highly aligned carbon nanotube arrays thin film grown from single feedstock for field emission," Journal of Nanoelectronics and Optoelectronics, vol. 8, no. 2, pp. 177-181, 2013.

[36] B. B. Wang, Q. J. Cheng, X. Chen, and K. Ostrikov, "Enhancement of electron field emission of vertically aligned carbon nanotubes by nitrogen plasma treatment," Journal of Alloys and Compounds, vol. 509, no. 38, pp. 9329-9334, 2011.

[37] T. Y. Tsai, N. H. Tai, and I. N. Lin, "Characteristics of carbon nanotube electron field emission devices prepared by LTCC process," Diamond and Related Materials, vol. 13, no. 4-8, pp. 982-986, 2004.

[38] W. I. Milne, K. B. K. Teo, G. A. J. Amaratunga et al., "Aligned carbon nanotubes/fibers for applications in vacuum microwave devices," Current Applied Physics, vol. 4, no. 5, pp. 513-517, 2004.

[39] S. R. P. Silva and J. D. Carey, "Enhancing the electrical conduction in amorphous carbon and prospects for device applications," Diamond and Related Materials, vol. 12, no. 2, pp. 151-158, 2003.
[40] X. C. LeQuan, W. P. Kang, J. L. Davidson, M. Guo, and B. K. Choi, "Micro-raman, SEM, XPS, and electron field emission characterizations of nitrogen-induced shallow defects on nanodiamond films fabricated with different growth parameters," Diamond and Related Materials, vol. 18, no. 2-3, pp. 191-195, 2009.

[41] P. Z. Zhang, R. S. Li, H. Yang, Y. C. Feng, and E. Q. Xie, "Enhanced electron field emission from $\mathrm{ZnO}$ nanoparticlesembedded DLC films prepared by electrochemical deposition," Solid State Sciences, vol. 14, no. 6, pp. 715-718, 2012.

[42] E. Fogarassy, T. Szorenyi, F. Antoni et al., "Influence of the nitrogen content on the field emission properties of a-CNx films prepared by pulsed laser deposition," Applied Surface Science, vol. 197-198, pp. 316-320, 2002.

[43] X. Yan, T. Xu, G. Chen, S. Xu, and S. Yang, "Field-emission properties of diamond-like-carbon and nitrogen-doped diamondlike-carbon films prepared by electrochemical deposition," Applied Physics A, vol. 81, no. 1, pp. 41-46, 2005.

[44] A. Majumdara, S. C. Das, R. Bogdanowicza, T. Shripathib, W. Langeld, and R. Hipplera, "Role of nitrogen in evolution of $\mathrm{sp}^{2} / \mathrm{sp}^{3}$ bonding and optical band gap in hydrogenated carbon nitride," Vibrational Spectroscopy, vol. 66, pp. 63-68, 2013.

[45] R. Wächter, A. Cordery, S. Proffitt, and J. S. Foord, "Influence of film deposition parameters on the field emission properties of diamond-like carbon films," Diamond and Related Materials, vol. 7, no. 2-5, pp. 687-691, 1998.

[46] S. H. Wan, L. P. Wang, J. Y. Zhang, and Q. J. Xue, "Field emission properties of DLC and phosphorus-doped DLC films prepared by electrochemical deposition process," Applied Surface Science, vol. 255, no. 6, pp. 3817-3821, 2009.

[47] J. J. Li, W. T. Zheng, Z. S. Jin et al., "Electron field emission of radio frequency magnetron sputtered $\mathrm{CNx}$ films annealed at different temperatures," Journal of Vacuum Science and Technology B, vol. 21, no. 6, pp. 2382-2387, 2003.

[48] Y. Umehara, S. Murai, Y. Koide, and M. Murakami, "Effects of $\mathrm{sp}^{2} / \mathrm{sp}^{3}$ bonding ratios on field emission properties of diamondlike carbon films grown by microwave plasma chemical vapor deposition," Diamond and Related Materials, vol. 11, no. 7, pp. 1429-1435, 2002.

[49] J. J. Li, W. T. Zheng, and H. J. Bian, "The effect of annealing on the field emission properties of amorphous CNx films," Acta Physica Sinica, vol. 52, no. 07, pp. 1797-1801, 2003.

[50] Y. B. Zhang, S. P. Lau, L. Huang, Z. Sun, and B. K. Tay, "Microstructure effect on field emission from tetrahedral amorphous carbon films annealed in nitrogen and acetylene ambient," Diamond and Related Materials, vol. 13, no. 1, pp. 133-138, 2004.

[51] O. S. Panwar, M. A. Khan, M. Kumar et al., "Effect of high substrate bias and hydrogen and nitrogen incorporation on filtered cathodic vacuum arc deposited tetrahedral amorphous carbon films," Thin Solid Films, vol. 516, no. 8, pp. 2331-2340, 2008.

[52] O. S. Panwar, M. A. Khan, B. S. Satyanarayana et al., "Effect of high substrate bias and hydrogen and nitrogen incorporation on density of states and field-emission threshold in tetrahedral amorphous carbon films," Journal of Vacuum Science and Technology B, vol. 28, no. 2, pp. 411-422, 2010.

[53] B. S. Satyanarayana, A. Hart, W. I. Milne, and J. Robertson, "Field emission from tetrahedral amorphous carbon," Applied Physics Letters, vol. 71, no. 10, pp. 1430-1432, 1997.

[54] X. Shi, L. K. Cheah, B. K. Tay, and S. R. P. Silva, "Electron field emission from surface treated tetrahedral amorphous carbon films," Applied Physics Letters, vol. 74, no. 6, pp. 833-835, 1999. 
[55] J. D. Carey, R. D. Forrest, R. U. A. Khan, and S. R. P. Silva, "Influence of $\mathrm{sp}^{2}$ clusters on the field emission properties of amorphous carbon thin films," Applied Physics Letters, vol. 77, no. 13, pp. 2006-2008, 2000.

[56] B. Zhang, Y. L. Yu, Z. Wang, and J. Y. Zhang, "Structure evolution from nanocolumns to nanoporous of nitrogen doped amorphous carbon films deposited by magnetron sputtering," Applied Surface Science, vol. 256, no. 22, pp. 6506-6511, 2010.

[57] F. Tuinstra and J. L. Koenig, "Raman spectrum of graphite," The Journal of Chemical Physics, vol. 53, no. 3, pp. 1126-1130, 1970.

[58] R. Paul, S. Dalui, and A. K. Pal, "Modulation of field emission properties of DLC films with the incorporation of nanocrystalline silver nanoparticles by CVD technique," Surface and Coatings Technology, vol. 204, no. 24, pp. 4025-4033, 2010.

[59] L. Lin, H. J. Niu, M. L. Zhang, W. Song, Z. Wang, and X. D. Bai, "Electron field emission from amorphous carbon with N-doped nanostructures pyrolyzed from polyaniline," Applied Surface Science, vol. 254, no. 22, pp. 7250-7254, 2008.

[60] U. Hoffmann, A. Weber, C.-P. Klages, and T. Matthée, "Field emission of nitrogenated amorphous carbon films," Carbon, vol. 37, no. 5, pp. 753-757, 1999.

[61] R. S. Li, E. Q. Xie, M. Zhou, Z. X. Zhang, T. Wang, and B. A. Lu, "Field emission properties of nitrogen incorporated DLC films prepared by electrodeposition," Applied Surface Science, vol. 255, no. 5, pp. 2787-2790, 2008.

[62] R. McCann, S. S. Roy, P. Papakonstantinou et al., "NEXAFS study and electrical properties of nitrogen-incorporated tetrahedral amorphous carbon films," Diamond and Related Materials, vol. 14, no. 3-7, pp. 1057-1061, 2005.

[63] J. J. Li, C. Z. Gu, P. Xu, Q. Wang, and W. T. Zheng, "Field emission enhancement of carbon nitride films by annealing with different durations," Materials Science and Engineering B, vol. 126, no. 1, pp. 74-79, 2006.

[64] Y. J. Li, S. P. Lau, B. K. Tay et al., "Field emission from tetrahedral amorphous carbonn films with various surface morphologies," Diamond and Related Materials, vol. 10, no. 8, pp. 1515-1522, 2001.

[65] X. B. Yan, T. Xu, G. Chen, S. R. Yang, and H. W. Liu, "Study of structure, tribological properties and growth mechanism of DLC and nitrogen-doped DLC films deposited by Electrochemical technique," Applied Surface Science, vol. 236, no. 1, pp. 328335, 2004.

[66] G. Chen, X. B. Yan, H. W. Liu, and T. Xu, "The microstructure comparison of DLC and CNx films deposition by Electrochemical," Journal of Chinese Electron Microscopy Society, vol. 23, no. 4, p. 430, 2004.

[67] S. B. Wei, T. M. Shao, and J. Xu, "Effect of bombarding energy of $\mathrm{N}$ ions on composition, hardness and surface free energy of carbon nitride films," Surface and Coatings Technology, vol. 206, no. 19-20, pp. 3944-3948, 2012.

[68] A. Hart, B. S. Satyanarayana, W. I. Milne, and J. Robertson, "Field emission from tetrahedral amorphous carbon as a function of surface treatment and substrate material," Applied Physics Letters, vol. 74, no. 11, pp. 1594-1596, 1999.

[69] H. Akasaka, T. Yamada, and N. Ohtake, "Effect of film structure on field emission properties of nitrogen doped hydrogenated amorphous carbon films," Diamond and Related Materials, vol. 18, no. 2-3, pp. 423-425, 2009.

[70] D. S. Mao, J. Zhao, W. Li et al., "Electron field emission from nitrogen-containing diamond-like carbon films deposited by filtered arc deposition," Materials Letters, vol. 41, no. 3, pp. 117121, 1999.
[71] P. H. Cutler, N. M. Miskovsky, P. B. Lerner, and M. S. Chung, "The use of internal field emission to inject electronic charge carriers into the conduction band of diamond films: a review," Applied Surface Science, vol. 146, no. 1-4, pp. 126-133, 1999.

[72] Š. Meškinis, R. Gudaitis, V. Kopustinskas, S. Tamulevičius, and K. Šlapika-Piezoresistive, "Optical and electrical properties of diamond like carbon and carbon nitride films," Diamond and Related Materials, vol. 19, no. 10, pp. 1249-1253, 2010.

[73] J. Schwan, V. Batori, S. Ulrich, H. Ehrhardt, and S. R. P. Silva, "Nitrogen doping of amorphous carbon thin films," Journal of Applied Physics, vol. 84, no. 4, pp. 2071-2081, 1998. 

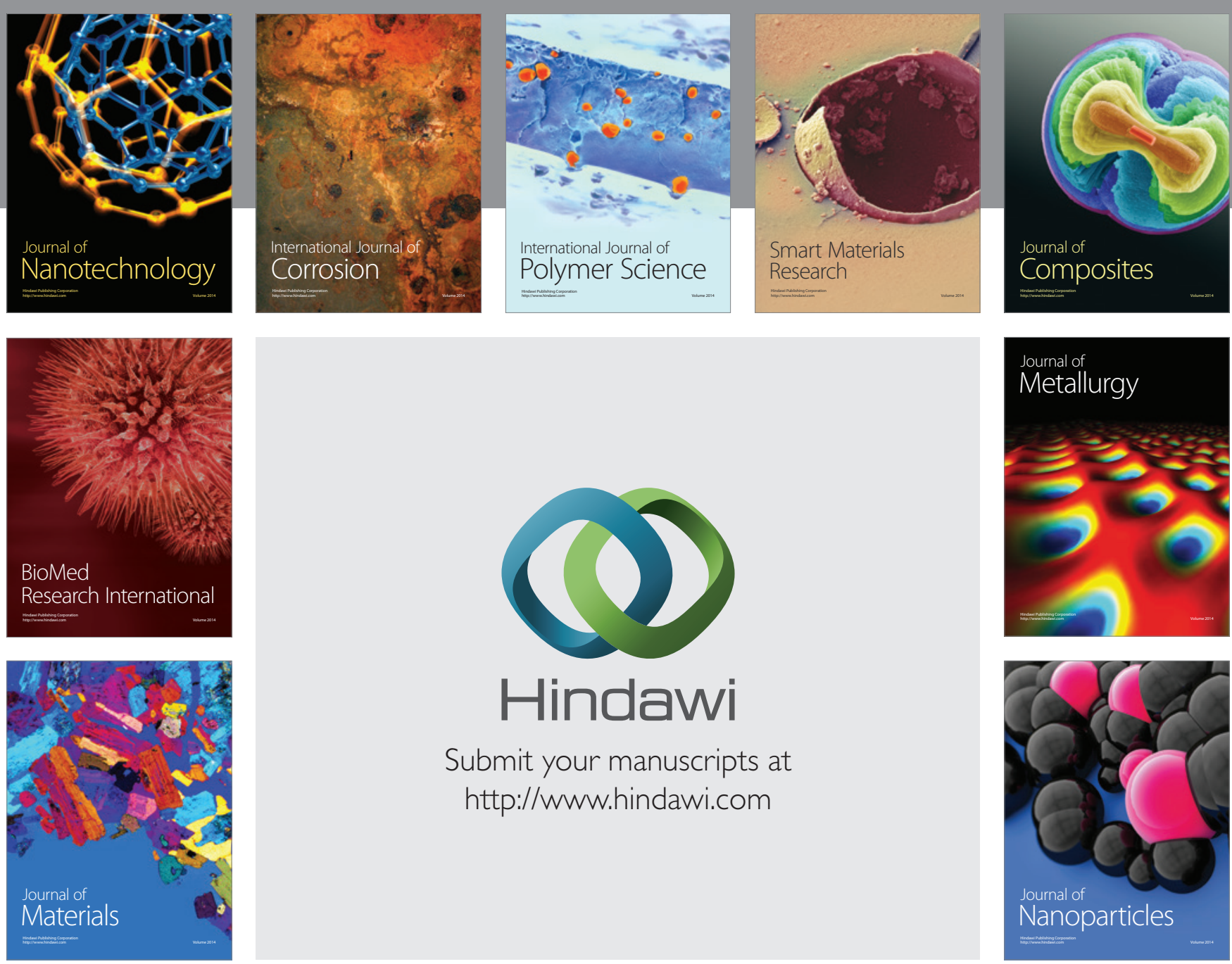

Submit your manuscripts at http://www.hindawi.com
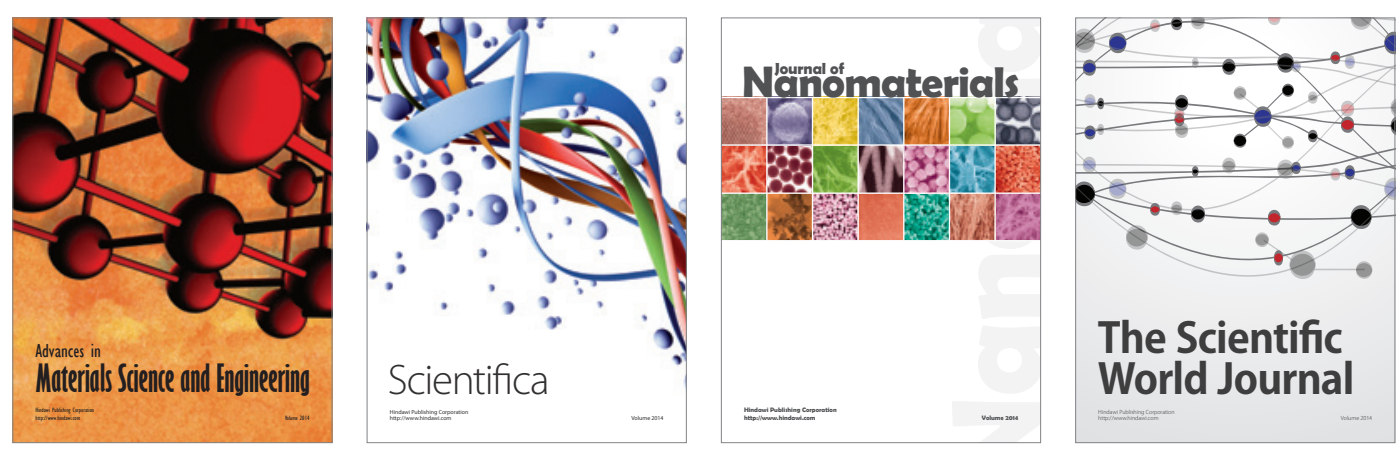

\section{The Scientific World Journal}
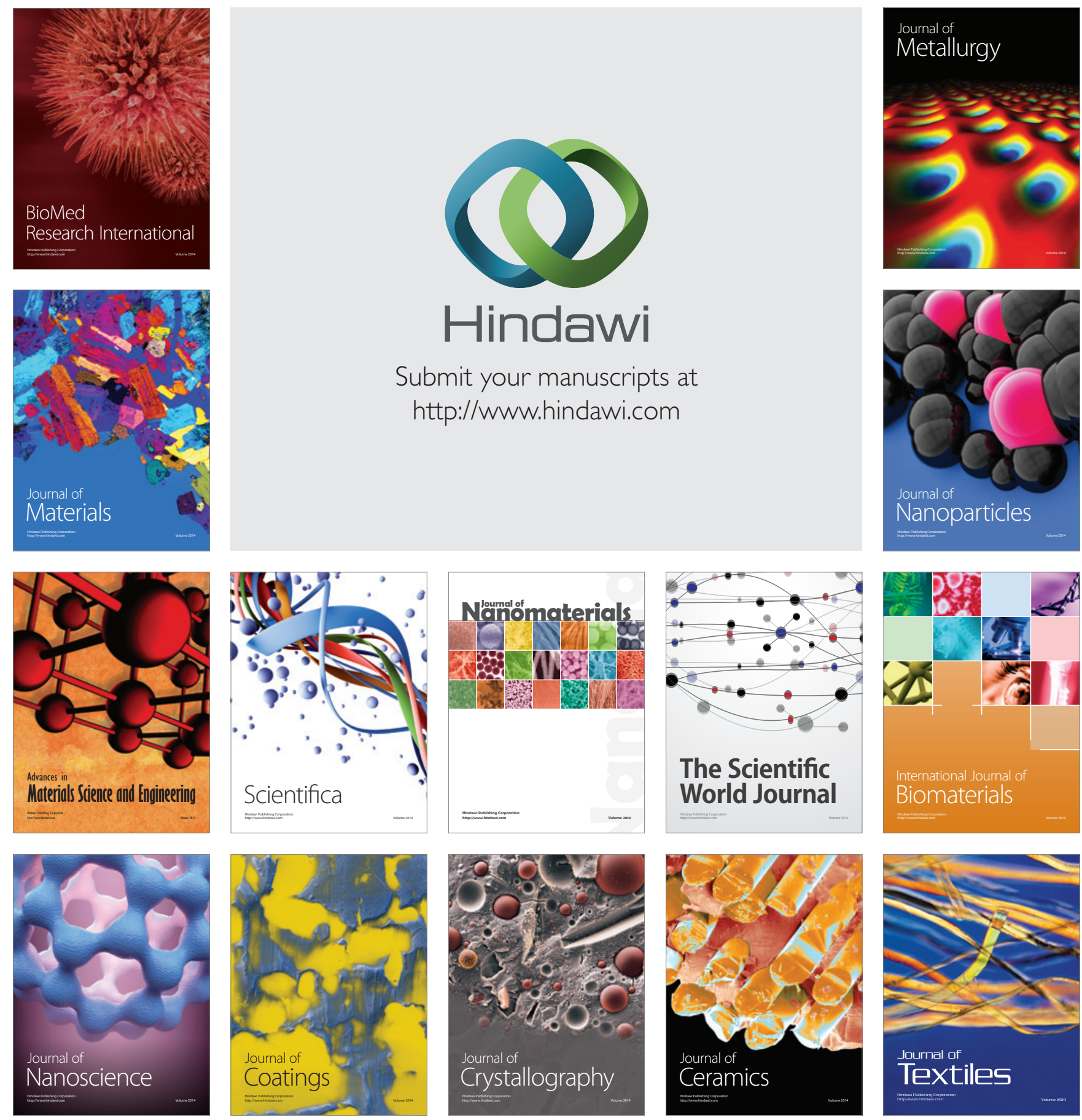